Olena Azarenko, Yuliia Honcharenko, Mykhailo Diviziniuk, Yevhen Ivanov, Volodymyr Mirnenko, Iuliia Surytsia, Volodymyr Oliferuk (2019) Protsess razvitiya chrezvyichaynoy situatsii na ohranyaemom ob'ekte kriticheskoy infrastrukturyi [The process emergency development at a protected critical infrastructure facility]. Social development \& Security. 9 (6), 132-146.

DOI: http://doi.org/10.33445/sds.2019.9.6.11

\title{
Процесс развития чрезвычайной ситуации на охраняемом объекте критической инфраструктуры
}

\section{Елена Азаренко *, Юлия Гончаренко **, Михаил Дивизинюк ***, Владимир Мирненко ****, Юлия Сирица *****, Владимир Олиферук ******}

\section{* Национальный авиационный университет,} пр-кт Мирослава Гузара, 1, г. Киев, 030058, Украина,

д.ф.-м.н., профессор, e-mail:fkkpi@nau.edu.ua, декан факультета

** Европейский университет,

б-р Академика Вернадского, 16В, г. Киев, 03142, Украина,

д.т.н., доцент,

e-mail:vup@e-u.in.ua,

nрофессор кафедры

*** Институт геохимии и окружающей среди НАН Украины, пр-кт Академика Палладина, 34а, г. Киев, 03142, Украина,

д.ф.-м.н., профессор,

e-mail:divizinyuk@ukr.net,

заведуюший отделом

**** Национальный университет оборони Украины имени Ивана Черняховского, пр-кт Воздухофлотский, 28, г. Киев, 03049, Украина,

д.т.н., профессор, Заслуженный работник образования Украины,

e-mail: mirnenkovi@gmail.com,

заведуюший кафедры

***** Национальный университет оборони Украины имени Ивана Черняховского, пр-кт Воздухофлотский, 28, г. Киев, 03049, Украина,

e-mail: burchyk2@gmail.com,

преподаватель кафедры

****** Национальный университет оборони Украины имени Ивана Черняховского, пр-кт Воздухофлотский, 28, г. Киев, 03049, Украина,

e-mail: oliferuk211278@gmail.com,

начальник отдела 
ISSN 2522-9842@ Social development \& Security, Vol. 9, No. 6, - 2019

\section{OPEN ACCESS}

Article history:

Received: November 20, 2019

1st Revision: December 5, 2019

Accepted: December 30, 2019

Аннотация: в работе дается описание процесса развития чрезвычайной ситуации на охраняемом объекте критической инфраструктуры в интересах последующей разработки моделей опасных явлений, специфических для каждого предприятия. Первоначально сформулированные постулаты, определяющие решение фундаментальных и прикладных задач, связанных с понятием (термином) чрезвычайная ситуация. Во-первых, это объективный пространственно-временной процесс, который имеет свои пространственные и временные масштабы. Во-вторых, этот процесс протекает в пространстве, определенном соответствующими пространственными масштабами. В-третьих, этот процесс определяется кратковременным событием или совокупностью кратковременных событий, в период которых один или несколько параметров, описывающих ситуацию или происходящее событие, изменяются с наибольшими (максимальными, экстремальными) градиентами. С учетом этих постулатов, для описания чрезвычайной ситуации как пространственно-временного процесса необходимо использовать три критерия, а именно: четкое определение типа катастрофического события, в результате которого формируется исследуемая чрезвычайная ситуация, вероятность наступления этого события и степень снижения его негативных последствий.

Процесс развития чрезвычайной ситуации опирается на главную отправную точку катастрофическое событие, которое может произойти. Тогда пространственно-временной процесс развития чрезвычайной ситуации состоит из пяти основных этапов. Первый - этап повседневного накопления негативных факторов. Второй - этап экстремального накопления одного или нескольких негативных факторов. Третий этап - само катастрофическое событие. Четвертый этап - этап ликвидации последствий катастрофического события. Пятый этап отдаленные последствия катастрофического события.

Ключевые слова: чрезвычайная ситуация, катастрофическое событие, охраняемый объект, объект критической инфраструктуры, авария, сценарий.

Библ.: 7, рис. 1.

\section{1. Формулирование проблемы}

\section{1. Анализ последних исследований и публикаций.}

Проблема обеспечения безопасности опасных техногенных производств появилась одновременно с созданием первых опасных техногенных объектов. Изучением различных аспектов этой проблемы занимались не только инженерно-технический и административный персонал предприятий, но и ученые различных областей знаний. С течением времени в конце прошлого века появились новые научно-прикладные направления как управление безопасностью предприятия, управление техногенной безопасностью, культура безопасности и другие $[1 ; 2]$. Вопросы управления безопасностью, как и любой другой управленческой деятельностью, основываются на двух направлениях [3]. Первое - это накопление и систематизация данных и знаний об авариях и катастрофах, происшествиях и других опасных фактах, отвечающих специфике и техногенному циклу предприятия. Их последующий анализ позволяет осуществлять прогноз возможных аварийных ситуаций, а на их основе разработку превентивных мероприятий в интересах недопущения негативных происшествий. Разрабатываются так же мероприятия на случай наступления этих негативных событий с целью минимизации последствий в результате их 
наступления и их последующей ликвидации. Второе направление предусматривает моделирование процесса появления негативного события, его развития и последствий, наступающих в результате его наступления. Процесс многоразового моделирования позволяет так же разрабатывать превентивные и ликвидационные мероприятия, однако в отличие от первого направления, он позволяет делать количественную, а не качественную оценку. Безусловно, точность количественных оценок будет определяться точностью модели, описывающий этот процесс $[4 ; 5]$.

В основу описания процесса развития чрезвычайной ситуации на охраняемом объекте критической инфраструктуры положены описания чрезвычайных ситуаций, происходящих с водными транспортными средствами [6], вызванные разливом нефтепродуктов [7] и на других потенциально опасных объектах [6].

\section{2. Постановка задания}

Целью данной работы является описание процесса развития чрезвычайной ситуации на охраняемом объекте критической инфраструктуры в интересах последующей разработки моделей опасных явлений, специфических для каждого предприятия.

Для достижения заданной цели необходимо решить следующие задачи. Первоначально определить критерии для описания чрезвычайной ситуации как пространственно-временного процесса. Затем дать характеристику процесса развития чрезвычайной ситуации на объекте критической инфраструктуры и его составных частей.

Объектом исследования есть процесс развития чрезвычайной ситуации на охраняемом объекте критической инфраструктуры.

\section{2. Изложение основного материала}

\section{1. Определение критериев для описания чрезвычайной ситуации как} пространственно-временного процесса.

При описании некоторого исследуемого пространственно-временного процесса необходимо определить начальные условия решения задачи и цели его изучения [3-5].

Начальные условия - это четко сформулированные постулаты, определяющие решение фундаментальных и прикладных задач, связанных с понятием (термином) чрезвычайная ситуация.

Во-первых, это объективный пространственно-временной процесс, который имеет свои пространственные и временные масштабы.

Во-вторых, этот процесс протекает в пространстве, определенном соответствующими пространственными масштабами.

В-третьих, этот процесс определяется кратковременным событием или совокупностью кратковременных событий, в период которых один или 
несколько параметров, описывающих ситуацию или происходящее событие, изменяются с наибольшими (максимальными, экстремальными) градиентами.

В нашем случае описание процесса ЧС необходимо для построения модели, позволяющей исследовать происходящие на объекте критической инфраструктуры пространственно-временные процессы. Задавая набор параметров разработанной модели, а затем, изменяя их, можно получить определенные результаты, которые называют выборками данных. Изучение зависимостей между выборками позволяет создавать алгоритмы, отражающие моделируемый процесс. Но для этого необходимо определить критерии, в соответствии с которыми будет описываться моделируемый процесс.

Моделируемый процесс - это развитие ЧС на объекте критической инфраструктуры. Он тесно связан с аварией, катастрофой или другим пришествием, которое принято называть катастрофическим событием $[1 ; 2]$. Строго говоря, авария - это частный случай общей закономерности. Необходимо отметить, что авария - это более узкое понятие, чем ЧС, происходящая на объекте критической инфраструктуры. Это ее составная часть. Авария - это катастрофическое событие.

Авария (от арабского «авар» - повреждение, ущерб) - неожиданный выход из строя, который повлек за собой повреждение техники, в результате чего она требует ремонта или подлежит списанию.

С учетом вышесказанного основой для описания ЧС является именно тип катастрофического события, которое может произойти. Например, на энергоблоке АЭС могут произойти катастрофические события, вызванные авариями из-за повреждения активной зоны реактора, разгерметизации первого контура, потери конденсата второго контура. Все эти три независимых друг от друга события могут привести к радиоактивному загрязнению окружающей среды. Каждому из них соответствует набор вполне определенных моделей в зависимости от сочетания конкретных технических факторов, для которых уже разработаны управляющие алгоритмы, позволяющие держать ситуацию под контролем и управлять ею. Взяв за основу более общее катастрофическое событие - радиоактивное заражение местности, необходимо сделать более громоздкую модель, составными частями которой являются три предыдущие и еще три десятка моделей, учитывающих факторы, отражающие особенности технологического цикла АЭС.

Второй критерий - это вероятность происхождения катастрофического события, которая может зависеть от множества факторов, но как было показано выше, чем конкретнее информация о возможном катастрофическом событии, тем проще модель, описывающая его, тем совершенней будет алгоритм, позволяющий прогнозировать и воздействовать на протекание процесса ЧС. Вероятность возникновения или наступления катастрофического события как функция времени позволит наглядно отображать процесс и качественно оценивать ситуацию.

Третий критерий, отражающий ситуацию после наступления катастрофического события, показывает степень снижения негативных последствий, численно определяется вероятностью снижения уровня последствий. В ряде 
случаев степень снижения негативных последствий может быть оценена коэффициентом снижения уровня последствий, который численно равен объему фактических потерь (затрат, убытков и другое) к максимально возможным (максимально расчетным). Соответственно, чем ниже значение коэффициента, тем выше степень снижения негативных последствий, и наоборот.

Таким образом, для описания чрезвычайной ситуации как пространственновременного процесса необходимо использовать три критерия, а именно: четкое определение типа катастрофического события, в результате которого формируется исследуемая чрезвычайная ситуация, вероятность наступления этого события и степень снижения его негативных последствий.

\section{2. Характеристика процесса развития чрезвычайной ситуации на объекте критической инфраструктуры и его составные части.}

Процесс развития ЧС опирается на главную отправную точку катастрофическое событие, которое первоначально может произойти. Далее это процессы, которые развивались до наступления аварии или катастрофы, и определили ее возникновение. Затем процессы, которые развиваются после катастрофического события, его последствия [6-8].

Как пространственно-временной процесс, ЧС состоит из пяти основных этапов. Первый - этап повседневного накопления негативных факторов. Второй - этап экстремального накопления одного или нескольких негативных факторов. Третий этап - само катастрофическое событие. Четвертый этап - этап ликвидации последствий катастрофического события. Пятый этап - отдаленные последствия катастрофического события.

Первый этап, так или иначе, - это накопление предпосылок, способствующих появлению катастрофического события. Этому предшествует множество событий объективного и субъективного характера. Очень сложно определить, когда именно начинается обратный отсчет времени наступления трагедии. Например, существуют жесткие нормы определения надежности электрических кабелей и соединений, путем замера их сопротивления изоляции. Понижение значений сопротивления изоляции свидетельствует о нарушении герметичности кабельной трассы. Необходимо принимать комплекс соответствующих мер. В зависимости от назначения кабельной линии данные величины необходимо определять раз в квартал, раз в месяц, раз в неделю или ежедневно. Пренебрежение этими работами в течение определенного времени (например, года или месяца) приводит к внезапному пробою кабельной трассы и пожару.

Другим примером может служить ежедневная проверка дежурных дизель генераторов. Они запускаются и работают в течение определенного времени. В них поддерживается полный запас топлива и масла. В зимнее время, особенно в условиях отрицательных температур дежурный дизель генератор запускается через промежутки времени, обеспечивающие его температурный режим и автоматический запуск. Пренебрежение этими вопросами, может привести к тому, что при отключении внешнего электропитания, реакторные системы будут обесточены (трагедия Фокусимы). 
Кроме того, каждый сотрудник при трудоустройстве должен быть ознакомлен с законодательной базой, действующей в государстве, и нормативными документами, ее регламентирующими (техникой безопасности по определенным видам работ, требованиями по безопасной эксплуатации приборов и оборудования, инструкциями по охране труда, правилами противопожарной безопасности и другими), и неукоснительно их выполнять. При этом на предприятиях, транспорте и в других организациях (тем более на охраняемых объектах критической инфраструктуры) систематически должны проводиться профилактические мероприятия, предусмотренные в соответствующих должностных инструкциях. Возможно, что в силу непредвиденных или субъективных причин, некоторые из них не выполняются. Например, по болезни мастера пропущена очередная проверка сопротивления изоляции силового резервного кабеля на предприятии или из-за отсутствия транспорта отложен на продолжительный срок осмотр дренажных стоков оползневого склона, которые должны проходить с определенной периодичностью, что приводит к накоплению повседневного негативного фактора, который, в конечном итоге, может привести к аварии или катастрофе.

Продолжительность этого этапа неограниченна. Он определяется повседневной жизнью на объектах критической инфраструктуры. Накопление негативных факторов проявляется в изменении вероятности возникновения катастрофического события, которая может увеличиваться или уменьшаться. Она может осознаваться или нет, вычисляться или качественно оцениваться руководством, но когда эти колебания достигают критического порога - в момент времени, то происходит переход к следующему этапу, как показано на рис.1.

Тогда первый этап переходит во второй - экстремального накопления одного или нескольких негативных факторов, обуславливающих ЧС. Это объективный процесс, который происходит, независим от нашего сознания.

Факт экстремального накопления негативных факторов должен быть выявлен и по устранению его первопричин должно быть принято управленческое решение, которое будет соответствующим образом реализовываться. Другими словами, экстремальное накопление негативного фактора и реакция на него происходит не сразу, а через определенный промежуток времени.

Второй этап определяется как период перехода непосредственно к экстремальной ситуации и называется этапом экстремального накопления негативных факторов или экстремального развития ситуации. Суть его состоит в том, что множество факторов, описывающих состояние техногенного или природного объекта, указывает на рост риска возникновения ЧС. Это означает, что процесс равновесного состояния фактически вышел из-под контроля. В приведенных выше примерах в первом случае - это падение сопротивления изоляции силового кабеля и возникновение опасности короткого замыкания и пожара, а во втором - это забитые (загрязненные) части дренажных стоков оползневого склона и насыщение его влагой, что в любой момент может вызвать оползень и привести к обвалу дороги, проходящей рядом. Наступление второго этапа объективно, но его еще необходимо осознать и начать действовать. 


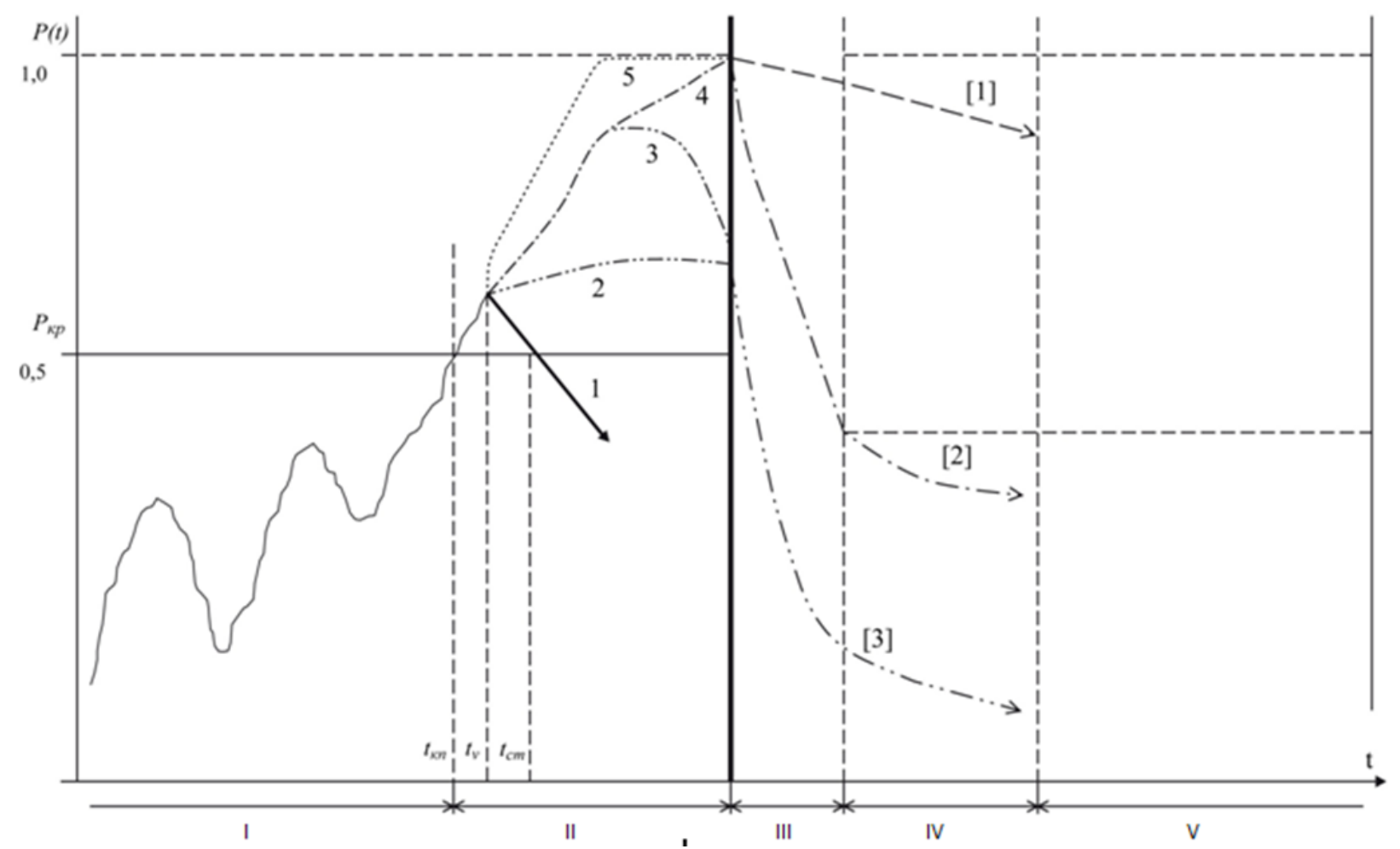

Рис.1. Схема этапов чрезвычайной ситуации.

На графике (рис. 1) описанному состоянию соответствует точка - начало экстремального (чрезвычайного) управления, которое происходит в момент времени. Здесь возможно пять типовых сценариев развития событий. Первый, когда экстремальная ситуация начинает развиваться, но принятыми мерами все предпосылки возможных аварий и катастроф оперативно ликвидируются в кратчайший промежуток времени. Наступает момент стабилизации, когда вся система (предприятие, природный объект и другое) возвращается в исходное состояние, где по-прежнему происходят различные процессы накопления повседневных негативных факторов. Такой сценарий называют благоприятным (рис.1, линия 1).

Второй сценарий называется оперативным. Он состоит в том, что принятыми мерами риск (вероятность возникновения аварии или катастрофического события) остается достаточно высоким, но ситуация находится под контролем, однако первоначальные причины остаются не устраненными и сохраняются довольно долго в силу сложности или продолжительности их нейтрализации (рис.1, линия 2).

Третий сценарий развития событий - «балансирование на грани». Об этом случае говорят иногда, как о чуде, о чем-то фантастическом, невозможном, когда, казалось бы, уже неизбежная катастрофа не происходит благодаря комплексу принятых мер, усилий, действий, стечению обстоятельств и других факторов. Дальнейшими действиями ситуация сводится ко второму, а затем первому сценариям (рис. 2.1, линия 3). В результате получается балансирование на грани с позитивным исходом. 
Четвертый сценарий - балансирование на грани с негативным исходом, когда не удается сдержать ситуацию, и катастрофическое событие все-таки наступает (рис.1, линия 4). Эти названия третий и четвертый сценарии получили, так как напоминают движение канатоходца на высоте. Он идет от одного края к другому по тонкой струне, балансирует, удерживая равновесие. Одно неверное движение и падение - катастрофа.

К сожалению, иногда не принятие мер приводит в смене второго сценария на третий, а затем - на четвертый. Например, гибель теплохода «Адмирал Нахимов» на рейде Новороссийска. Выход теплохода «Адмирал Нахимов» из Новороссийской бухты и подход к порту Новороссийск сухогруза «Петр Васев» происходило в ночное время в штилевую погоду. Отличная видимость огней вызвала пренебрежение радиолокационной проводкой целей на обоих судах. Оба судна двигались вне зон разделения. Сочетание этих негативных факторов случайным образом привела к критической ситуации. Критическая ситуация это относительно небольшой промежуток времени, когда все факторы сводятся к критической точке. Здесь логично провести аналогию с точкой возврата, преодолев которую, водное транспортное средство или воздушное судно уже не может вернуться назад (не хватит топлива, моторесурса и другое). Критическая ситуация не обязательно может завершиться аварией, здесь ее еще можно избежать. На примере гибели теплохода «Адмирал Нахимов» критической точкой была подача неправильной команды на сухогрузе об остановке главной машины и даче заднего хода. По инерции сухогруз мог пройти более семи миль. Но вращение винта в обратном направлении привела к потере управляемости судном - оно не слушалось руля. Аналогичная ситуация произошла с «Титаником», когда была подана команда об остановке главных машин и даче полного хода назад. Не останавливая их, а дав команду на руль, и «Петр Васев», и «Титаник» могли избежать столкновения.

Классическим примером непринятия мер является трагедия, произошедшая в 2010году на рейде Севастополя, где стояли десятки судов, когда поступило предупреждение об усилении ветра до 30 м/с западного направления. Практически все суда ушли на рейд Ялты, где обеспечивается надежное укрытие от ветров западного и северного направлений. Переход на рейд Ялты - это уход назад, который ведет к дополнительному расходу топлива. Часть судов зашла в Севастополь для укрытия от шторма. Это также является дополнительными затратами, оплата происходит за каждый метр причальной стенки. Только грузинское судно «Хадж-Измаил» осталось стоять на рейде. Сутки оно простояло без особых происшествий, но, когда сорвался шквальный ветер северо-западного направления, судно не смогло стоять на якоре - его стало сносить на берег. Зайти в Севастополь или дойти до Ялты оно не могло и затонуло на рейде Севастополя.

Возможен также и пятый сценарий. Это такая ситуация, при которой предотвратить катастрофу уже ничем невозможно. Она наступит строго по времени. Это похоже на ситуацию в горном поселке, расположенном в долине. В горах уже сошла лавина. Она с огромной скоростью движется вниз, сметая все на своем пути. Поселок она накроет через десятки минут, обратный отчет уже начат.... Но поселок пока живет своей жизнью. 
Поэтому этот сценарий называют неотвратимым. Лавинообразное развитие событий таково, что чрезвычайная ситуация неизбежна. В этом случае промежуток времени, оставшийся до наступления катастрофы, можно использовать для принятия мер, позволяющих уменьшить потери среди населения, возможный материальный ущерб и масштабы последствий. Например, загорелась струйка бензина из поврежденного бензобака при дорожно-транспортном происшествии. С момента воспламенения до взрыва проходит несколько секунд, которых может быть недостаточно для того, чтобы потушить огонь, но наверняка хватит, чтобы отбежать и упасть на землю и уменьшить воздействие взрывной волны. Или другой фактический пример. Землетрясение в декабре 2004 года в Индийском океане зафиксировали все сейсмостанции мира, и практически все геофизики высказались о том, что возникнет гигантская волна - цунами. С момента фиксации землетрясения до прихода цунами прошло от нескольких десятков минут до полутора часов, в зависимости от расстояния до эпицентра. Десятки людей ушли на возвышенности. Абсолютное большинство людей не поверила этому сообщению. Они не ушли с побережья. В результате - более двухсот тысяч погибших.

В экстремальной практике подобную ситуацию называют временем последнего момента. Наиболее показательным примером действий последнего момента является событие, произошедшее у Фолклендских островов. Атака аргентинских самолетов на английский конвой. Крылатая ракета французского производства «Экзосет» идет на высоте 15 метров и наводится в середину английского судна комплексного снабжения, где расположены топливные танки с авиационным топливом. Ракета обнаружена на расстоянии 8-10 кабельтовых (1500-1800 метров). Ее скорость 180-200 м/с. Подлетное время 7-10 секунд. Но с ее обнаружением командир английского судна комплексного снабжения отдает команду на стрельбу установкой для постановки пассивных помех. Через 3-4 секунды облако пассивных дипольных помех окружает носовую часть судна и крылатая ракета, захватив их, изменяет траекторию своего движения. Взрыв ракеты происходит в носовой надстройке судна. Оно повреждено, но он остается на плаву и сохраняет ход. Возникший пожар в носовой надстройке (это не танки с авиационным топливом) ликвидируется экипажем.

Второй этап развития ЧС характеризуется некоторыми сложностями информационного плана. С одной стороны, законодательные акты государств, как правило, обязывают исполнительные органы информировать граждан обо всех событиях, оказывающих негативное влияние на их жизнь и здоровье, а с другой стороны - неправильно поданная информация может вызвать панику среди населения. Так, например, любое сообщение с ядерного объекта, каковыми являются атомные электростанции, о нештатной ситуации вызывает у граждан реакцию, называемую Чернобыльским синдромом или фактором Фокусимы. Здесь особую роль играет целостность поданной информации. Если освещать развитие ЧС не в полном объеме, а только выдергивать отдельные факты из контекста, то такое информирование населения может стать источником новых ЧС, только уже социального характера. Они будут проявляться в массовом отъезде граждан, скупкой долгохранящихся продуктов и другое. 
Следует также отметить, что когда ситуация развивается по относительно благоприятному (второму или третьему) сценарию, то есть привлечение дополнительных сил и средств позволяет держать все под контролем, может случиться так, что любая неосторожно высказанная информация, попавшая в руки некомпетентных людей, может привести к негативным последствиям среди населения. В связи с этим обстоятельством весь информационный обмен должен быть конфиденциальным. Это относится и к информации о развитии ЧС, и к информации, используемой в технологических процессах, а также к сведениям, поступающим во взаимодействующие подразделения, оказывающим помощь в интересах предотвращения экстремальной обстановки.

Другими словами, во время второго этапа возможно несколько типовых сценариев развития событий. Первый сценарий - это когда принятыми мерами риск аварии или катастрофы, увеличившийся после появления экстремальных обстоятельств, значительно снижается. Второй - когда принятыми мерами величину этого риска удается удержать на прежнем уровне. Третий - принятые меры не стабилизируют ситуацию, риск катастрофы продолжает расти, но она не происходит. Четвертый - в отличии от третьего сценария катастрофа все-таки происходит. Пятый - неотвратимый, когда катастрофическое событие неотвратимо происходит, а оставшееся время необходимо использовать для минимизации его последствий.

Третий этап развития чрезвычайной ситуации - это само катастрофическое событие, авария, взрыв, пожар и другое. Этот этап может быть скоротечным (до нескольких минут) и более длительным (несколько суток и более). Если оно скоротечно, например, обвал дороги, взрыв моста, столкновение поездов, падение самолета и другое, то время соответствует времени возникновения катастрофы. Если же оно продолжительно, как, например, наводнение, извержение вулкана, лесной пожар и другое, то - это время начала катастрофического события. С момента начала оно проходит фазы развития, апогея, затухания и прекращения. Например, для последнего события на английском судне комплексного снабжения. Попадание ракеты, взрыв, возгорание горючих веществ и материалов на корабле - это начало события. Затем распространение огня, увеличение площади пожара, рост температуры горения и другое - это развитие события, которое достигает своего апогея наивысшей точки развития. Принимаемыми мерами пожар тушится, уменьшается площадь возгорания - это затухание события. Наконец, пожар полностью потушен и осмотром всех помещений новых источников возгорания не обнаружено - это окончание события.

На рис.1 показано, что в результате применения управленческих действий, эффективность которых характеризуется коэффициентом снижения негативных последствий, изменяется величина ущерба. В первом случае ущерб близок к максимальному (значение коэффициента близко к единице - линия [1]). Во втором случае (линия [2]) - ущерб уменьшен в 2 раза, и в третьем (линия [3]) ущерб сведен к минимуму.

Четвертый этап - ликвидация последствий катастрофического события. Он, как и третий этап, так же характеризуется степенью снижения ожидаемого 
ущерба и является этапом прогностических и ликвидационных мероприятий. Если катастрофическое событие скоротечное, то меры по ликвидации последствий наступают сразу после третьего этапа. Например, столкновение судов, и, как следствие, разлом одного из них с последующим скоротечным затоплением. Это третий этап, который сразу же перерастает в четвертый спасение людей, оказавшихся в воде.

В случае, когда катастрофическое событие носит длительный характер, например, посадка танкера на мель и разлив нефтепродуктов из поврежденных танков, необходимо выполнение прогностических расчетов вероятных последствий разлива, определение необходимых сил и средств для его локализации и реализация ликвидационных мероприятий. Расчеты выполняются в кратчайший срок с тем, чтобы минимизировать возможные негативные последствия. Этап ликвидации последствий аварии может длиться от нескольких дней до нескольких месяцев и завершится тогда, когда все основные признаки и последствия катастрофического события ликвидированы, и нет никакой угрозы нормальной повседневной жизни и деятельности людей.

Пятый этап - отдаленные последствия, которые могут проявляться через десятки месяцев (например, появление вторичных нефтяных загрязнений в результате всплытия на водную поверхность подводных объемных эмульгированных нефтяных загрязнений морской и океанической водной толщи) или через десятки лет (например, у детей, родители которых принимали участие в ликвидации последствий Чернобыльской катастрофы).

Следовательно, процесс развития чрезвычайной ситуации на объекте критической инфраструктуры характеризуется пятью составными частями или этапами. Первый - этап повседневного накопления негативных факторов. Второй - этап экстремального накопления одного или нескольких негативных факторов. Третий этап - само катастрофическое событие. Четвертый этап - этап ликвидации последствий катастрофического события. Пятый этап - отдаленные последствия катастрофического события.

\section{3. Выводы и перспектива}

Таким образом, описание процесса развития чрезвычайной ситуации на охраняемом объекте критической инфраструктуры в интересах последующей разработки моделей опасных явлений, специфических для каждого предприятия, необходимо использовать три критерия. Первый - четкое определение типа катастрофического события, в результате которого формируется исследуемая чрезвычайная ситуация, второй - вероятность наступления этого события и третий - степень снижения его негативных последствий. Процесс развития чрезвычайной ситуации на объекте критической инфраструктуры характеризуется пятью составными частями или этапами. Первый - этап повседневного накопления негативных факторов. Второй - этап экстремального накопления одного или нескольких негативных факторов. Третий этап - само катастрофическое событие. Четвертый этап - этап ликвидации последствий катастрофического события. Пятый этап - отдаленные последствия катастрофического события. 
Author details (in Ukrainian)

\title{
Процес розвитку надзвичайної ситуації на об’єкті критичної інфраструктури, що охороняється
}

\author{
Олена Азаренко *, Юлія Гончаренко **, Михайло Дівізінюк ***, \\ Володимир Мірненко ****, Юлія Сириця *****, Володимир Оліферук ******
}

* Національний авіаційний університет, пр-кт Космонавта Комарова, 1, м. Київ, 030058, Україна,

д.ф.-м.н., професор,

e-mail:fkkpi@nau.edu.ua,

декан факультету

** Європейський університет,

б-р Академіка Вернадського, 16В, г. Київ, 03142, Україна,

д.т.н., доиент,

e-mail:vup@e-u.in.ua,

професор кафедри

*** Інститут геохімії навколишнього середовища НАН України,

пр-кт Академіка Палладіна, 34а, г. Київ, 03142, Украӥна,

д.ф.-м.н., професор,

e-mail:divizinyuk@ukr.net,

завідувач відділом

****Науіональний університет оборони України імені Івана Черняховського,

пр-кт Повітрофлотський, 28, г. Київ, 03049, Україна,

д.т.н., професор, Заслужений прачівник освіти Украӥни,

e-mail:mirnenkovi@gmail.com,

завідувач кафедри

***** Національний університет оборони України імені Івана Черняховського,

пр-кт Повітрофлотський, 28, г. Київ, 03049, Україна,

e-mail: burchyk2@gmail.com,

викладач кафедри

****** Національний університет оборони України імені Івана Черняховського,

пр-кт Повітрофлотський, 28, г. Київ, 03049, Украӥна,

e-mail: oliferuk211278@gmail.com,

начальник відділу

Анотація: в роботі надається опис процесу розвитку надзвичайної ситуації на об'єкті критичної інфраструктури, що охороняється, в інтересах подальшої розробки моделей небезпечних явищ, специфічних для кожного підприємства. Спочатку сформульовані постулати, що визначають вирішення фундаментальних і прикладних завдань, пов'язаних 3 поняттям (терміном) надзвичайна ситуація. По-перше, це об'єктивний просторово-часовий процес, який має свої просторові і тимчасові масштаби. По-друге, цей процес протікає в просторі, визначеному відповідними просторовими масштабами. По-третє, цей процес визначається короткочасною подією або сукупністю короткочасних подій, в період яких один 
або кілька параметрів, що описують ситуацію або відбувається подія, змінюються 3 найбільшими (максимальними, екстремальними) градієнтами. 3 урахуванням цих постулатів, для опису надзвичайної ситуації, як просторово-часового процесу, необхідно використовувати три критерії, а саме: чітке визначення типу катастрофічної події, в результаті якого формується досліджувана надзвичайна ситуація, ймовірність настання цієї події і ступінь зниження його негативних наслідків.

Процес розвитку надзвичайної ситуації опирається на головну відправну точку катастрофічна подія, яка може статися. Тоді просторово-часовий процес розвитку надзвичайної ситуації складається 3 п'яти основних етапів. Перший - етап повсякденного накопичення негативних факторів. Другий - етап екстремального накопичення одного або декількох негативних факторів. Третій етап - саме катастрофічна подія. Четвертий етап - етап ліквідації наслідків катастрофічної події. П'ятий етап - віддалені наслідки катастрофічної події.

Ключові слова: надзвичайна ситуація, катастрофічна подія, об'єкт, що охороняється, об'єкт критичної інфраструктури, аварія, сценарій.

Библ.: 7, рис. 1.

\title{
Author details (in English)
}

\section{The process of an emergency situation development at a guarded critical infrastructure facility}

\author{
Elena Azarenko *, Yuliia Honcharenko **, Mykhailo Divizinyuk ***, \\ Volodymyr Mirnenko ****, Iuliia Syrytsia *****, Volodymyr Oliferuk ****** \\ * National Aviation University, \\ Miroslav Husar Ave., 1, Kyiv, Ukraine, 03058, \\ Doctor of Science, Professor, \\ e-mail: fkkpi@nau.edu.ua, \\ Dean of the Faculty \\ ** European University, \\ Academician Vernadsky, 16B, Kyiv, Ukraine, 03142, \\ Doctor of Technical Sciences, Associate Professor, \\ e-mail:vup@e-u.in.ua, \\ Professor of the department
}

*** Institute of Environmental Geochemistry of National Academy of Sciences of Ukraine, Academician Palladin Ave., 34a, Kyiv, Ukraine, 03142,

Doctor of Science, Professor,

e-mail:divizinyuk@ukr.net,

Head of department

****National Defense University of Ukraine named Ivan Cherniakhovskyi,

Povitroflotsky Ave., 28, Kyiv, Ukraine, 03049,

Doctor of Technical Sciences, Professor, Honored Worker of Education of Ukraine,

e-mail: mirnenkovi@gmail.com,

Head of the department

*****National Defense University of Ukraine named Ivan Cherniakhovskyi,

Povitroflotsky Ave., 28, Kyiv, Ukraine, 03049, 
e-mail: burchyk2@gmail.com,

Lecturer of the department

****** National Defense University of Ukraine named Ivan Cherniakhovskyi,

Povitroflotsky Ave., 28, Kyiv, Ukraine, 03049,

e-mail: oliferuk211278@gmail.com,

Head of department

Abstract: In the paper, it is given a description of an emergency situation development at a guarded critical infrastructure facility in the interests of the subsequent development of hazardous phenomena models specific to each enterprise.

Primarily there have been formulated postulates that determine the solution of fundamental and applied tasks associated with the concept (term) of an emergency situation. Firstly, it is an objective spatio-temporal process that has its spatial and temporal scales. Secondly, this process takes place in a space defined by the corresponding spatial scales. Thirdly, this process is determined by a short-term event or a set of short-term events during which one or more parameters describing a situation or an occurring event change with the largest (maximum, extreme) gradients. Taken into account these postulates for the description of an emergency situation as a spatio-temporal process, it is necessary to use three criteria namely: a clear definition of the type of catastrophic event as a result of which the researched emergency situation is being formed, the probability of this event and a degree of reduction of its negative consequences.

The process of an emergency situation development bases on the main starting point, namely a catastrophic event that can happen. So the spatio-temporal process of an emergency situation development consists of five main stages. The first is the stage of everyday accumulation of negative factors. The second is the stage of extreme accumulation of one or several negative factors. The third stage - the catastrophic event itself. The fourth stage is the stage of liquidation of the consequences of a catastrophic event. The fifth stage is the long-term consequences of a catastrophic event.

Keywords: emergency situation, catastrophic event, guarded facility, critical infrastructure facility, accident, scenario.

References 7, figures 1 .

\section{Используемая литература}

1. Защита критической инфраструктуры государства от террористического воздействия / за ред. Дивизинюк М.М. Київ: Видавництво НУОУ ім. Івана Черняховського, 2018. 84 с. ISBN 978-617-7187-25-6

2. Информационно-технические методы предотвращения чрезвычайных ситуаций террористического характера на объектах критической инфраструктуры. Часть 1. С использованием активных импульсных радиолокационных средств / за ред. Дивизинюк М.М. Київ: Видавництво НУОУ ім. Івана Черняховського, 2019. 164 с. ISBN 978-617-718733-1

3. Герасимов Б.М., Дивизинюк М. М., Субач И. Ю. Системы поддержки принятия решений: проектирование, применение, оценка эффективности: монография. Севастополь: СНИЯЭиП, 2004. 318 с.

4. Tibshirani R. (1996) Regression shrinkage and selection via the lasso. Sonal of the Royal Statistical Society. Series B (Methodological). Vol. 58. № 1. - p. 267-288. URL: https://www.jstor.org/stable/2346178?seq=1

5. Воронцов К.В. Лекции по методам оценивания и выбору моделей. 2007. 25 с. URL: http://www.ccas.ru/voron/download/Modeling.pdf

6. Азаренко О.В., Гончаренко Ю. Ю., Дівізінюк М.М., Иванов Е.В., Мирненко В. І., Фаррахов О.В. (2019) Особливості управління надзвичайною ситуацією на водному транспортному 
засобі. Journal of Scientific Papers «Social development \& Security». № 9 (3). C. 137-152. DOI: 10.33445/sds.2019.9.3.11

7. Азаренко О.В., Гончаренко Ю.Ю., Дивизинюк М.М., Мирненко В.И., Тищенко Е.А. (2019) Управления чрезвычайной ситуации, вызванной разливом нефтепродуктов в территориальном море Украины. Social development \& Security. № 9 (2). C. 101-119. DOI: 10.33445/sds.2019.9.2.8

\section{References}

1. Zaschita kriticheskoy infrastrukturyi gosudarstva of terroristicheskogo vozdeystviya / za red. Divizinyuk M.M. Kyiv: Vidavnitstvo NUOU Im. Ivana Chernyahovskogo, 2018. 84 s. ISBN 978-617-7187-25-6

2. Informatsionno-tehnicheskie metodyi predotvrascheniya chrezvyichaynyih situatsiy terroristicheskogo haraktera na ob'ektah kriticheskoy infrastrukturyi. Chast $1 . \mathrm{S}$ ispolzovaniem aktivnyih impulsnyih radiolokatsionnyih sredstv / za red. Divizinyuk M.M. Kyiv: Vidavnitstvo NUOU Im. Ivana Chernyahovskogo, 2019. 164 s. ISBN 978-617-7187-33-1

3. Gerasimov B. M., Divizinyuk M. M., Subach I. Yu. Sistemyi podderzhki prinyatiya resheniy: proektirovanie, primenenie, otsenka effektivnosti: Monografiya. Sevastopol: SNIYaEiP, 2004. 318 s.

4. Tibshirani R. (1996) Regression shrinkage and selection via the lasso. Sonal of the Royal Statistical Society. Series B (Methodological). Vol. 58. № 1. p. 267-288. URL: https://www.jstor.org/stable/2346178?seq=1

5. Vorontsov K.V. Lektsii po metodam otsenivaniya i vyiboru modeley. 2007. 25 s. URL: http://www.ccas.ru/voron/download/Modeling.pdf

6. Azarenko O.V., Goncharenko Yu. Yu., DIvIzInyuk M. M., Ivanov E. V., MIrnenko V. I., Farrahov O. V. OsoblivostI upravlInnya nadzvichaynoyu situatsIEyu na vodnomu transportnomu zasobI. Journal of Scientific Papers "Social development \& Security". $2019 . \quad \# \quad 9$ (3). S. 137-152. https://doi.org/10.33445/sds.2019.9.3.11

9. Azarenko O.V., Divizinyuk M. M., Mirnenko V. I., Tischenko E. A. Upravleniya chrezvyichaynoy situatsii, vyizvannoy razlivom nefteproduktov v territorialnom more Ukrainyi. Social development \& Security. 2019. \# 9 (2). S. 101-119. https://doi.org/10.33445/sds.2019.9.2.8 